\title{
MANAGEMENT AND INFRASTRUCTURES IN A MARITIME COAL TERMINAL: A DECISION-MAKING METHODOLOGY
}

\author{
CRISTIANO MARINACCI ${ }^{1}$, STEFANO RICCI ${ }^{1}$, LUCA RIZZETTO $^{1} \&$ MARIA EUGENIA LOPEZ LAMBAS ${ }^{2}$ \\ ${ }^{1}$ Sapienza University of Rome - DICEA, Italy \\ ${ }^{2}$ Universidad Politecnica de Madrid, Spain
}

\begin{abstract}
The objective of this paper is to analyse the operational cycles of a coal terminal to identify development scenarios, conditioned by meteo-marine conditions, layout and equipment with the aim to reduce operational times. The scenarios include the construction of an offshore breakwater limiting the wave motion in the operational area, the extension of operational quays allowing the simultaneous handling of more ships, the building of multiple stocking areas to increase the stock capacity. This paper deals with technical analysis of operational schemes based on local constraining infrastructural and meteo-marine conditions as well as global effects of coal shipping delivery organisation. The method provides the useful elements to condition the key choices, both for investment prioritization and for the terminal management itself. The test is on the case study of a coal terminal feeding an electrical power plant nearby the port of Civitavecchia, Italy.
\end{abstract}

Keywords: transport, navigation, port, operation, terminal.

\section{INTRODUCTION}

The power plant Torrevaldaliga Nord was an oil thermoelectric power station, converted between 2003 and 2009 from oil to coal (Fig. 1). The plant has a total capacity of 1,980 MW, representing $50 \%$ of the electric energy needed by the Lazio Region and $4 \%$ of the national consumption. The technologies used to reconvert the plant and the exhaust system have allowed a remarkable decrease of pollutants making the plant a role model in reducing the environmental impact.

There was a net decrease of emissions of up to $61 \%$ of NOx and both $88 \%$ PM and SOx when the former oil system switched to the current coal one [1]. These values are $50 \%$ lower compared with the limits imposed by the EC to preserve health and environment. Coal is carried on bulk carriers moored in the docks for that purpose and then to the plant.

The terminal includes two right angle shaped docks: the main one for unloading and the other for loading operations. Coal bulk cargoes dock in the $400 \mathrm{~m}$ long main one, fitted for limestone and gravel also. The secondary dock, $260 \mathrm{~m}$ long, is for the export of gypsum and ashes and hence it is equipped only with facilities for these two types of powder.

The construction of the docks has faced difficulties linked to the seabed depth: the secondary dock is $16 \mathrm{~m}$ depth whilst the main one is $18 \mathrm{~m}$. The draught, i.e., the maximum depth of the submerged part of a solid bulk carrier, ranges from $8.1-22.0 \mathrm{~m}$, the length from 140 to $356 \mathrm{~m}$, the width from 18.7 to $57.0 \mathrm{~m}$ and the height from 10.5 to 28.8 , whilst the capacity varies from 10,000 to 300,000 tons.

Solid bulk carriers calling at Civitavecchia port have an average capacity of 80,787 tons; whilst the bigger ship entering the terminal in 2011 was 106,335 in gross tonnage (GT) and $12.21 \mathrm{~m}$ draught (empty). Moreover, due to navigation safety issues, a margin between the seabed and the fully loaded boat draught is necessary, which means in practice the inability to use the secondary dock to moor and unload the solid bulk carriers hauling coal. 


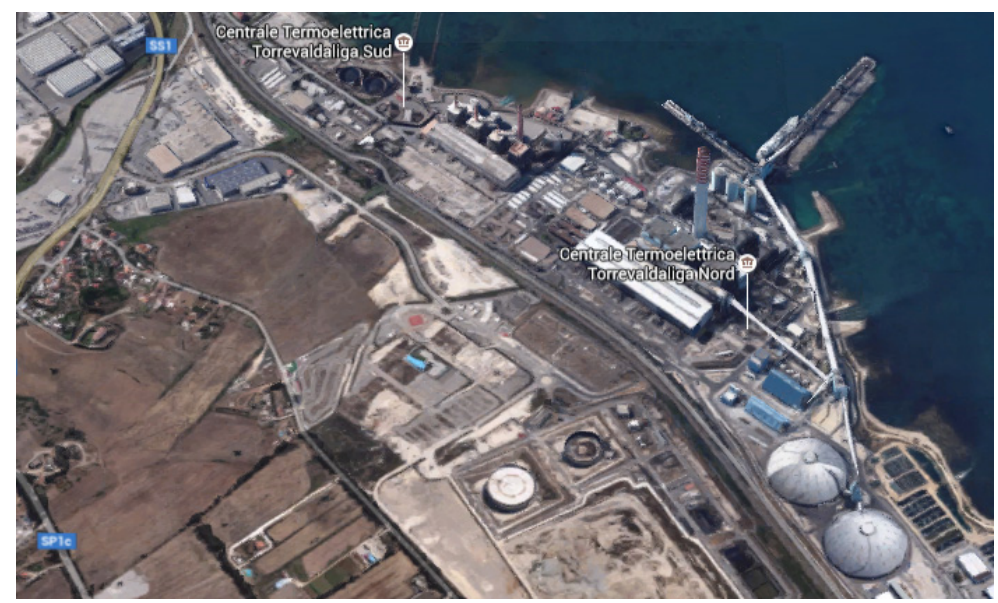

Figure 1: Power plant Torrevaldaliga Nord in Civitavecchia, Italy.

Therefore, the coal carriers can moor and unload only in the main dock, which is equipped with modern and environmentally friendly facilities for handling and unloading coal from the vessels by two continuous unloading stockpile conveyors (Fig. 2), each one able to load $1,500 \mathrm{t} / \mathrm{h}$ and up to $1,800 \mathrm{t} / \mathrm{h}$ in optimal conditions. The charge tube of the conveyor, which has a maximum capacity of $20,000 \mathrm{~kg}$, is enclosed in the hold and picks the coal. The fuel moves inside the tube and, thanks to the stockpile, arrives at the conveyor belts. In addition, to avoid the dispersion of the coal powder into the atmosphere, both the loading tube and the conveyor are sealed and dried.

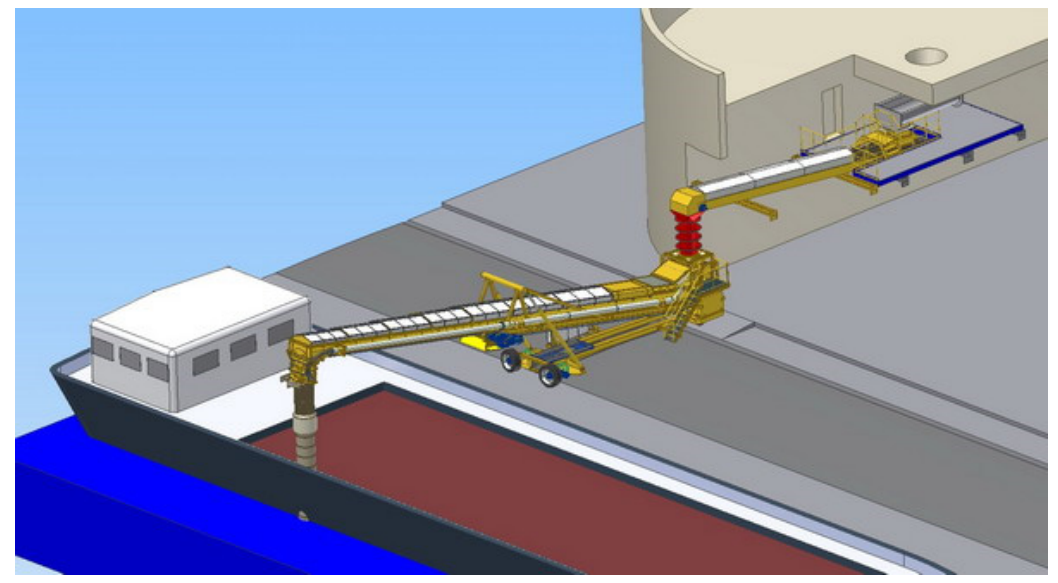

Figure 2: Typical stockpile conveyor.

The stockpile conveyors manually operate from the tower located $50 \mathrm{~m}$ high and two tracks allow a movement along the dock, so that the boat and each single stockpile conveyor can move autonomously. Once unloaded, the coal must reach the place designed for storage (carbonile dome) before channelling towards the boiler of the power plant (Fig. 3). 


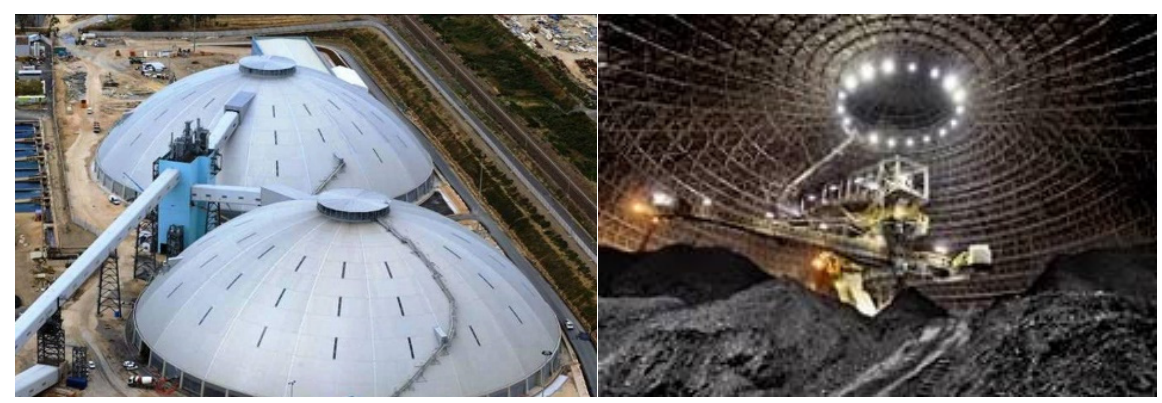

Figure 3: Carbonile domes at Torrevaldaliga Nord power plant.

A conveyor belt, completely sealed and covered to avoid any contact between coal, air and atmospheric agents, transfers the coal from the boat to the carbonile and further to the boiler. Once unloaded the coal, the conveyor belt along the dock picks it up and conveys it under the first tower, where an ash filter is located, with a maximum capacity of 3,000 t/h.

Successively, the coal is broken into pieces, conveyed into the dome, loaded again and conveyed through the belt to the boiler where the combustion will take place. Under the dome, there are two lines of bunkering ensuring the continuous flow of coal towards the boiler, even if one fails, and in case of urgency or crisis a direct belt line could transport the coal from the boat to the boiler, bypassing through the dome.

\section{TERMINAL OPERATING CYCLE}

\subsection{Definition}

Operating cycles includes all vessels' movement phases, from its arrival to the roadstead until its departure from the port once cargo has been unloaded. Nevertheless, it is useful to consider all the previous phases to the arrival in port in which it is necessary to comply with different requirements and complex documental practices. The two macro-areas in the operating cycles are:

- Preliminary stages, to the arrival to the roadstead (documentary phases).

- From the roadstead to the preliminary and subsequent unloading.

\subsection{Preliminary stages to the arrival to roadstead}

The first involved subject is the maritime agency, whose task is to connect the ship with the destination port, managing both the ship and the documentation. The agency contacts the coal terminal delivering the first data needed to organize the unloading schedule: Estimated Time of Arrival (ETA), unloading plan and characteristics of the cargo.

Independent surveyors monitor the cargo once arrived at the dock, measuring both its weight and quality, and checking the data at the end of the unloading. The surveyors' independence is a key issue since they shall ensure the validity of cargo and not favour any party to the dispute or cover possible damages suffered by them. Once the original documents are gathered (bill of lading, proforma invoice, certificate of origin, datasheet, shipper's declaration, port of origin, loading schedule), the vessel enters the computer system in such a way that the destination port can be confirmed or modified. Before the arrival to the roadstead, the custom is informed and the authorization for the partial unloading of the coal 
is given. At this point, the ship arrives to the roadstead, being the Notice Of Readiness (NOR) the document allowing the access to the port for the unloading phases.

\subsection{Following stages to unloading}

During all the documentary phases, the ship remains anchored at the roadstead pending the decision of the terminal, the Harbourmaster and customs surveyors for extra EU arrivals. At the terminal, the Unit for Movement of Coal (UMC) manages all the stages inside the port: the first check is the availability of the dome that, if negative, lets the ship remaining in the roadstead for a long time, being the costs of the delay in charge of the terminal.

Once verified the availability to unload the coal, the terminal sets the mooring orders, reported to Harbourmaster and maritime agency to get nihil ostat, activation of tugboats and procedures for the cleaning of the hold of the ship once unloaded. The UMC monitors and informs continuously surveyors and maritime agency about the mooring manoeuvres, which will be included and listed in the final documentation. Once the ship moored, the independent surveyors begin the arrival draft survey, as well the port chemist check the gas escape, which are both preliminary to the authorization of the unloading by the UMC.

During the unloading, a continuous updating is ongoing to identify reasons for eventual cargo delays, failures or damages. After the end of unloading, the surveyors board again the bulk carrier for the final draft survey of the total unloaded quantity and compares it with the evidence in the bill of lading. The exchange of documents takes place before the ship leaves the port, duly signed by all the parties: maritime agency, shipmaster and receiver. The signature allows the departure of the ships and the documentation is stored in the database according to ISO9001 compulsory certification.

\subsection{Potentially critical phases in the operating cycle}

All the phases described above suffers the influence of port location and configuration as well as the existing facilities: the regular development of the cycle is depending on existing infrastructural constraints:

- Lack of an outer protection from marine-meteorological events.

- Only one dock available for ship mooring and coal unloading.

- Limited storage capacity of the two coal domes.

Indeed, only in the last phase of the Civitavecchia Masterplan it is planned a breakwater to protect the entrance to the coal terminal. In the meantime, the lack of this infrastructure may cause serious problems in the mooring and unloading phases during intense meteorological events: the Harbourmaster does not allow at mooring or obliges to suspend the unloading operations. These events occur several times per year and oblige to interrupt, delay, overlap the phases or, finally, to take the extreme decision to let the ship leaving without unloading. Moreover, the presence of a single dock to unload the coal together with its limited length makes impossible the simultaneous unloading of two ships, with the rare exception of very small ships, anyway without simultaneous unloading. Finally, as mentioned above, the plant has two domes with a capacity of 150,000 t each and, hence, it is not possible to receive the cargo from two ships. Besides, the domes are specialized by coal quality to prevent self-ignition. Therefore, to optimize their performances, coal unloading of different quality should be alternate, consequently, whenever two ships unloading the same quantity and quality of coal approach the port, the UMC is obliged to the critical decision to leave a ship waiting at the roadstead, again with delays and potential ships overlaps. 


\section{OPERATIONAL ANALYSIS}

\subsection{Times analysis}

The focus is here on the time required by each phase of the operating cycles, analysed according to the recorded database of unloading operations, which allows at checking the annual performances and understanding the reasons for the losses of efficiency. The report records every operation (movement, waiting time, unloading, etc.) so that it is possible to differentiate the various phases within a cycle. This split of time is of key importance since, by assessing the weight of each phase, it is possible to compile the graphs that summarize the operativeness of the cycles.

The Key Performance Indicator (KPI) is the mass of coal unloaded per hour [t/h]. In Fig. 4, the KPI refers to the 58 ships moored in a typically year (2016) with the indication of average $(502 \mathrm{t} / \mathrm{h}$ and $426 \mathrm{t} / \mathrm{h})$ and maximum $(1,060 \mathrm{t} / \mathrm{h}$ and $1,231 \mathrm{t} / \mathrm{h})$ value, respectively for first and second semesters.

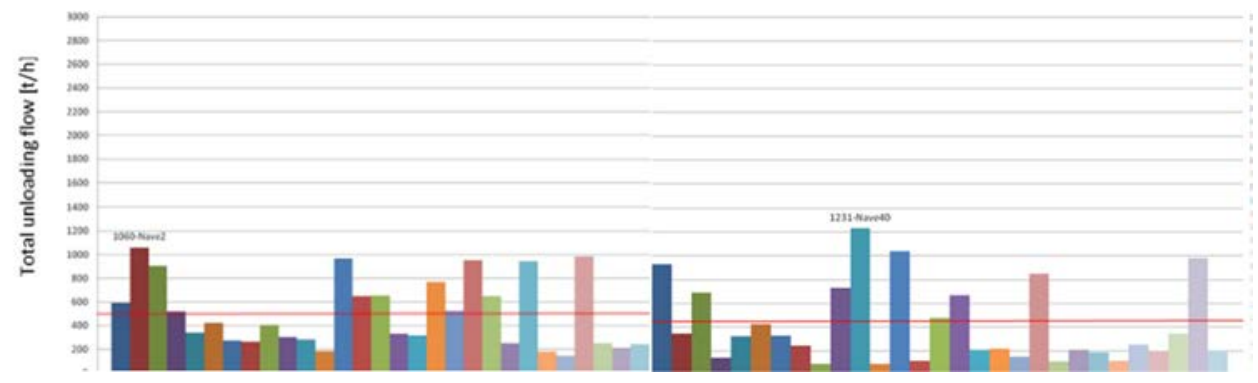

Figure 4: Masses of coal unloaded by 58 ships at the Torrevaldaliga Nord terminal.

The next key step is to isolate the non-operating times, identifying the reasons and calculating their duration as a guidance for potential improvements. Basing on these details, the occupation of the roadstead and the dock throughout the time span is under monitoring for each ship. Consolidated feedback is the presence of typical timeframes, e.g. night waiting time and transit time from the roadstead to the dock (60-90 min including waiting and operation of pilot and tugboats until the complete mooring and the serial/parallel documental phase), affected by the Harbourmaster regulations.

The begin of the unloading itself follows the completion of the arrival surveys, which has an average duration of $2 \mathrm{~h}$, if no further investigations are necessary as a consequence of emerging irregularities. The unloading time depends on the quantity: the average amount is around 70,000 t/ship, which requires around 3 days of unloading operation, followed by the final cleaning of the ship. Deviations by the average time could be consequent to:

- Failures: about 400 interruptions per year affecting the various equipment involved in the unloading itself and the transfer to the storage dome, generically identified as shore's mechanical breakdown.

- Bad weather conditions: mainly strong wind or rain causing interruptions lasting in the range of 90-150 min; very severe conditions cause longer interruptions, with the ship to be unmoored and approach a more protected area to prevent damages to the ship and the infrastructures themselves; weather cause interruptions affect $26 \%$ of the ships, particularly in spring and fall seasons. 
The global effects of these events on the unloading performances arise by calculating the net unloading times by excluding any typology of unplanned interruption. It makes the KPI (average unloading flows) represented in Fig. 4 increase respectively from 502 to 1,209 t/h in the first semester and from 426 to $1,365 \mathrm{t} / \mathrm{h}$, with $47 \%$ of ships overpassing this average value. All these values are anyway far away from the $3,000 \mathrm{t} / \mathrm{h}$, maximum operational capacity of the unloading equipment.

Moreover, secondary disruptions may be caused by the congestion generated by a prolonged unloading operation of the previous ship, temporary unavailability of storage capacity in the domes or finally incompleteness of commercial documentation, which both generates forced ship waiting in the roadstead.

\subsection{Costs analysis}

The economic effects of these prolonged times may be estimated, though the confidentiality of the commercial information does not allow to relate directly these estimation with the sea freight. In more detail [2], the generalised cost perceived by a customer depends on the global transport chain, including the maritime section, such as:

$$
C_{g}=\sum_{i} a_{n i} w_{n i}+\sum_{j} b_{M j} w_{M j}+\sum_{k} d_{U k} w_{U k},
$$

where $a, b, d$ are costs to use the single transport services: land based $(T)$; maritime $(M)$; and intermodal $(U)$, and $w$ terms represent cost coefficients related to reliability of single transport services.

By focusing only on the maritime section:

$$
b_{M j}=\beta_{M J} L_{M j}+\frac{G_{M j} L_{M j}}{V_{M j}},
$$

where

- $\quad \beta_{M j}[$ Euro/km]: unit cost of transport on maritime section $j$;

- $\quad L_{M j}[\mathrm{~km}]:$ distance along maritime $\operatorname{section} j$;

- $G_{M j}\left[\right.$ Euro/h] $=g r / t_{M j}$ : cost due to immobilisation of capital $g$ corresponding to transported goods; before trade of goods (approximately the duration of transport) such capital generates a cost, to be financed, depending on discount rate $r$ (approximately a credit transfer according to simple interest law) by immobilisation time $t_{M j}$

- $t_{M j}=L_{M j} / V_{M j}[\mathrm{~h}]$ : capital immobilisation time corresponding to value of goods

- $V_{M j}[\mathrm{~km} / \mathrm{h}]$ : commercial speed corresponding to maritime section $j$.

The derivation of unknown unit costs is possible according to the structure of contracts in force among agency, carriers and terminal operators [3].

For this specific analysis, the results of a systematic survey provide an apportionment of costs for different maritime transport modes: container, solid and liquid bulk, Ro-Ro and general cargo [4]. Within the solid bulk, the maritime freight for coal is variable on threemestral basis, without relevant worldwide differentiations by country of origin, in the range $19.0-20.7 \$ / \mathrm{t}$.

Moreover, another interesting parameter calculated in Banca d'Italia [4] is the average freight for the bulk carriers, which, for a ship with a capacity of about $65,000 \mathrm{t}$, is 25,272 $\$ /$ day. These data are very relevant for the evaluation of the economic advantages achievable by the possible implementation of new operational and infrastructural scenarios. 


\section{NEW OPERATIONAL AND INFRASTRUCTURAL SCENARIOS}

\subsection{Qualification of scenarios}

Starting from the study on operational times developed in Section 3, the aim is here to define new operational and infrastructural scenarios capable to increase the operational performances of the terminal and a related economic saving of the generalised cost of coal transport.

In this respect, the focus is on disruptions caused by dock or dome occupation, as well as bad weather conditions, which are sensible to infrastructural upgrades, therefore excluding failures to the equipment.

The new scenarios are including the following infrastructural improvements:

- Breakwater protection to reduce drastically the interference of the waves on the unloading operation and to prevent the suspensions of unloading due to the bad meteo conditions.

- New dock or prolongment of the existing one to ensure the simultaneous unloading of two ships and to prevent the waiting at the roadstead due to the occupancy of the dock by a previous ship;

- New dome to increase the storage capacity of about 150,000 t of coal and to prevent the waiting at the roadstead due to the unavailability of the storage assets.

For the economic evaluations, the key parameter is the daily ship freight calculated according to the methodology defined in Section 3, which helps to quantify the savings due to the reduced times that are not operational of the ships due to the terminal. Moreover, the combination of the scenarios allows at quantifying the potential operational synergies among them. The summary of the results achieved for all the considered scenarios is in Fig. 5.

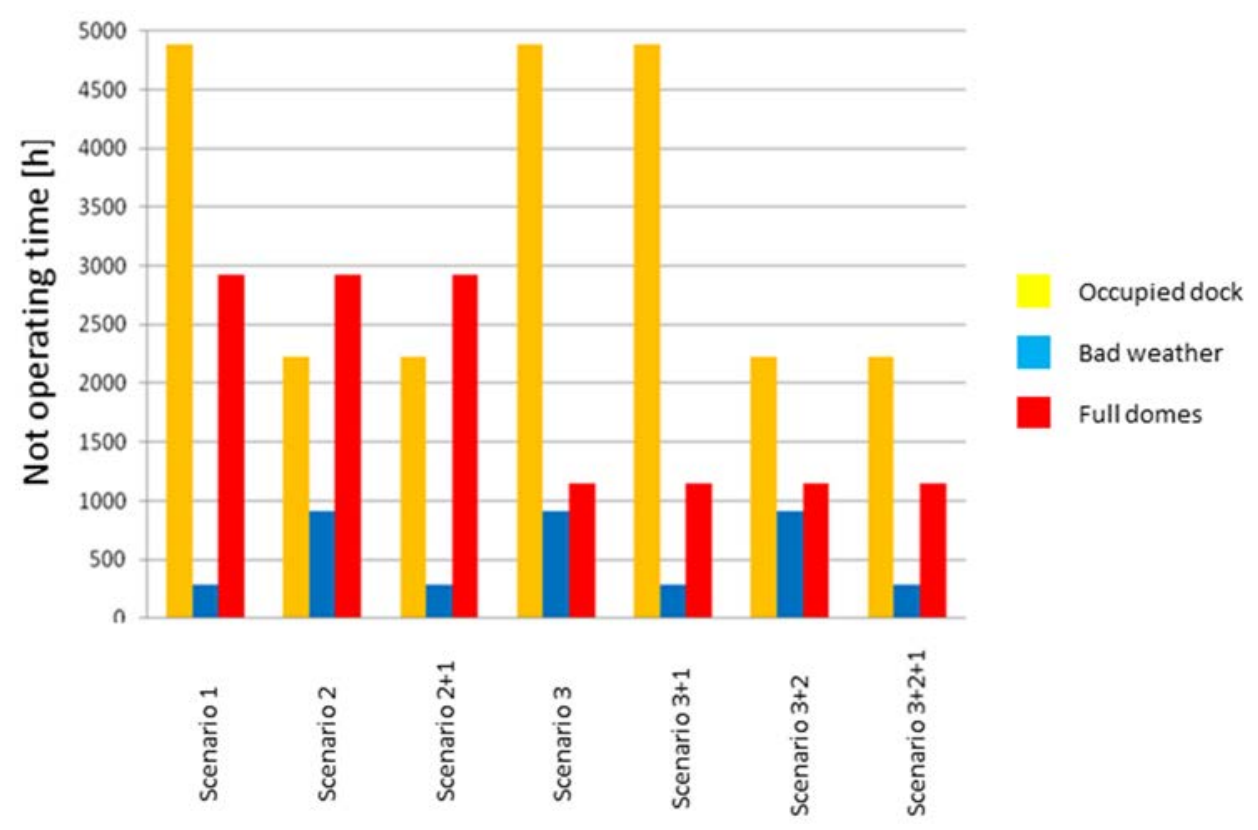

Figure 5: Residual non-operating time by causes in new potential scenarios. 


\subsection{Effects of scenario 1}

The basic assumption is that the breakwater is capable to prevent $67 \%$ of the times that are not operational caused by the bad meteo conditions (the residual part is due to extreme meteo conditions banning anyway the unloading operation). The global saving is $624 \mathrm{~h} /$ year (26 days/year) corresponding to an economic saving in maritime freights of about $657,000 \$ /$ year (about 587,000 Euro/year).

\subsection{Effects of scenario 2}

The basic assumption is that the possibility to unload two ships simultaneously prevent all waiting times of a second arrived ship during the unloading of another one. The global saving is 2,664 h/year (111 days/year) corresponding to an economic saving in maritime freights of about 2,800,000 \$/year (about 2,500,000 Euro/year).

\subsection{Effects of combined scenarios $2+1$}

The basic assumption is the total synergy between the two scenarios with a global additive effect. Therefore, global saving is 3,288 h/year (137 days/year) corresponding to an economic saving in maritime freights of about 3,387,000 \$/year (about 3,024,000 Euro/year).

\subsection{Effects of scenario 3}

The basic assumption is that the new dome is capable to prevent $53 \%$ of the waiting time caused by the unavailability of storage capacity (the residual part is due to waiting amount of coal exceeding the capacity of the new dome). The global saving is $1,776 \mathrm{~h} /$ year (74 days/year) corresponding to an economic saving in maritime freights of about $1,870,000$ \$/year (about 1,670,000 Euro/year).

\subsection{Effects of combined scenarios $3+1$}

The basic assumption is again the total synergy between the two scenarios with a global additive effect. Therefore, the global saving is $2,400 \mathrm{~h} /$ year (100 days/year) corresponding to an economic saving in maritime freights of about 2,527,000 \$/year (about 2,256,000 Euro/year).

\subsection{Effects of combined scenarios $3+2$}

The basic assumption is once more the total synergy between the two scenarios with a global additive effect. Therefore, the global saving is $4,440 \mathrm{~h} /$ year ( 185 days/year) corresponding to an economic saving in maritime freights of about 4,670,000 \$/year (about 4,170,000 Euro/year).

\subsection{Effects of combined scenarios $3+2+1$}

The basic assumption for the combination is, in the case too, the total synergy among the three scenarios with a global additive effect. Therefore, the global saving is 5,064 h/year (211 days/year) corresponding to an economic saving in maritime freights of about 5,327,000 \$/year (about 4,756,000 Euro/year). 


\section{CONCLUSIONS}

The original technical analysis carried out on the operational cycle of the coal terminal is the key issue of this paper. This analysis allowed identifying a number of proposals to reduce non-operating times and, hence, to increase the economic efficiency of the coal terminal. Moreover, it represents a key step for any approach basing on the simulation of the processes, used in the literature for coal [5] as well as other typologies of terminal approached by the same research group [6]-[8], anyway fed by a preliminary careful analysis of the operating cycles.

The methodology includes a cost model for the estimation of the positive economic effects of the various potential investments, key element to feed the economic and/or financial analysis dedicated to assessing their rate of return. To each scenario, correspond terminal developments, which, once implemented, would improve the current operating conditions with different impact levels. However, the identification of the best scenario applicable to the terminal needs some more specific economic knowledge, fed by more detailed information on freights and charter contracts, difficult to collect due to the confidentiality of data and commercial strategies of operators, which, anyway, falls outside the scope of the methodological engineering subject of this paper.

Nevertheless, the current Masterplan of Civitavecchia port includes the building of a new breakwater to prevent adverse meteorological conditions influencing mooring and unloading operations of coal carriers' ships. Therefore, the positive effects produced by Scenario 1 will be achievable as soon as the implementation of the Masterplan will be complete. The most effective infrastructural improvement of the terminal appears to be the increase of the dock capacity, by building a new one or prolonging the existing one.

The results of this study represent a methodological milestone to proceed with future indepth full comparative cost-benefit studies taking into account additional parameters.

\section{REFERENCES}

[1] ENEL, Stato dei Fatti delle navi Carbone, Civitavecchia, 2011.

[2] Ricci, S., Maritime Transport. Lectures 25/02/2019-31/05/2019, Sapienza Università di Roma, 2019.

[3] Robinson, R., Regulating efficiency into port-oriented chain systems: Export coal through the Dalrymple Bay terminal, Australia. Maritime Policy and Management, 34, 2007.

[4] Banca d'Italia, Indagine Campionaria sui Trasporti Internazionali. Benchmark, 2011, Roma, 2012.

[5] Harris, G.A., Holden, A., Schroer, B.J. \& Moeller, D.P.F., Coal terminal simulation. Conference Proceedings, of Huntsville Simulation Conference, 2007.

[6] Ricci, S., Marinacci, C. \& Rizzetto, L., The modelling support to maritime terminals sea operation: The case study of port of Messina. Journal of Maritime Research, 9(3), 2012.

[7] Ricci, S., Capodilupo, L. \& Tombesi, E., Discrete events simulation of intermodal terminals operation: Modelling techniques and achievable results. Civil Comp Proceedings, 110, 2016.

[8] Capodilupo, L., Furiò Pruñonosa, S., Marinacci, C., Ricci, S. \& Rizzetto, L., Analytical methods and simulation models to assess innovative operational measures and technologies for rail port terminals: the case of Valencia Principe Felipe terminal. XII Conference on Transport Engineering CIT 2016, 2016. 